\title{
APPLICATION OF ADVANCED OXIDATION PROCESS FOR THE REMOVAL OF SYNTHETIC WATER-BASED PRINTING DYE AND MICROPLASTICS FROM AQUEOUS SOLUTION
}

\author{
Miljana Prica ${ }^{1}$ (D), Aleksandra Tubić ${ }^{2}$ (D), Maja Lončarski ${ }^{2}$, Vesna Gvoić $^{1}$ (D), \\ Sanja Vasiljević ${ }^{2}$, Živko Pavlović ${ }^{1}$ (D), Jasmina Agbaba ${ }^{2}$ \\ ${ }^{1}$ University of Novi Sad, Faculty of Technical Sciences, Department of Graphic Engineering and \\ Design, Novi Sad, Serbia \\ ${ }^{2}$ University of Novi Sad, Faculty of Sciences, Department of Chemistry, Biochemistry and \\ Environmental Protection, Novi Sad, Serbia
}

\begin{abstract}
Starting from the assumption that wastewater treatments can have a significant impact on the interactions between microplastics (MPs) and various pollutants in different matrices, a focus must be directed on examination of classic and redesigned treatments to remove synthetic dyes in the presence of MPs from wastewater. This paper investigates the potential application of Fenton-like process for the removal of water-based printing dye (Cyan) from aqueous solution containing MPs in a form of granulated polyethylene (PEg). The influence of five quantitative parameters on decolorization efficiency was investigated: initial dye concentration (20-180 mgL ${ }^{-1}$ ), nano zero valent iron (nZVI) dosage (0.75-60 mgL $\mathrm{L}^{-1}$ ), PEg concentration (1-10 $\mathrm{gL}^{-1}$ ), hydrogen-peroxide concentration (1-11 mM) and $\mathrm{pH}$ value (2-10). A novel statistical approach, definitive screening design, resulted with the optimization process which yielded highest removal efficiency of $92 \%$ under following conditions: initial dye concentration of $155 \mathrm{mgL}^{-1}, \mathrm{nZVI}$ dosage of $55 \mathrm{mgL}^{-1}, \mathrm{PEg}$ concentration of $2.35 \mathrm{gL}^{-1}, \mathrm{H}_{2} \mathrm{O}_{2}$ concentration of $2 \mathrm{mM}$ and $\mathrm{pH}$ value 2.5. Available data indicate that in the future, wastewater containing MPs will dictate ways to reuse this water in terms of closing the water material cycle and reducing environmental pollution. Therefore, the industrial wastewater reuse is an important component of sustainable wastewater management practices, namely, water resource augmentation and pollutant reduction.
\end{abstract}

Key words: microplastics, printing dye, definitive screening design, optimization, Fenton-like process

\section{INTRODUCTION}

Microplastics (MPs) pollution is raising environmental concern in recent years due to its global distribution. MPs are plastic particles smaller than $5 \mathrm{~mm}$ in size, which can be classified as primary and secondary MPs, according to the source. Primary MPs are produced in a small size on purpose (toothpastes, facial cleaners, cosmetic products, resin balls, drug carriers, etc.), whereas secondary MPs are formed by degradation of larger plastic waste via physical, chemical and biological processes. Because of their low density and small particle size, they are easily discharged into the wastewater drainage systems. Therefore, the municipal wastewater treatment plants are indicated to be the main recipients of MPs before getting discharged into the natural waterbodies (Gulliver, 2017).

Printing inks and varnishes are industrial mixtures. In the manufacture process of certain printing dyes, polymers as resins and waxes are an essential ingredient, used in order to provide superior adhesion of dyes to non-porous surfaces. These polymers may fall under the proposed definition of MPs: solid nonbiodegradable polymeric particle with physical dimensions between $1 \mu \mathrm{m}-5 \mathrm{~mm}$ originating from anthropogenic sources. Additionally, MPs and dyes can be found in wastewater after the printing process on the polymer packaging material, or screens that are usually made of polyethylene or polypropylene, mainly in flexo and screen-printing process (Somalu et al, 2017; Pekarovicova and Huskova, 2016). In that way, MPs can act as a carrier of synthetic dyes, heavy metals and other toxic contaminants. Printing wastewater due to the presence of non-biodegradable compounds, high concentrations of chemical oxygen demand (COD), trace amounts of toxic metals, persistent colors, adhesives, pigments and etc. must be treated before discharging to water streams (Collivignarelli et al, 2019). The presence of synthetic waterbased dyes and MPs in industrial wastewater poses a threat to aquatic ecosystems, as well as a source of indirect negative effects on human health. Commonly applied method for COD and dye removal from industrial wastewaters are: electrocoagulation (Hendaoui et al, 2020), flocculation (Feng et al, 2021), adsorption (Atrous et al, 2019), biological methods (Mojtabavi et al, 2020), advanced oxidation processes (Kecić et al, 2018a), either individually or combined with other physicochemical methods, as well as nano- 
technology (Papadopoulos et al, 2019). However, classical wastewater treatments are not designed for the removal of synthetic dyes in the presence of MPs. That is why the improvement of technologies for the removal of various pollutants in the presence of MPs is an extremely important field of research.

The aim of this study is directed on examination of advanced oxidation treatment based on the Fenton-like process to remove synthetic water-based Cyan dye in the presence of MPs, polyethylene. Nano zero valent iron (nZVI) particles were synthesized by using green-tea leaves and utilized as a catalyst in Fenton-like process.

\section{MATERIALS AND METHODS}

\subsection{Materials and chemicals}

Water-based printing dye, Cyan, was produced from Flint group and obtained from one printing facility in Novi Sad, Serbia. Structure and properties of Cyan dye are presented in Table 1. Hydrogen peroxide, 30\% (NRK Engineering, Serbia), sodium hydroxide, >98.8\% (POCH), $\mathrm{CCH}_{2} \mathrm{SO}_{4},>96 \%$ (J.T. Baker) were of analytical grade and used without any further purification.

Table 1: Structure and properties of Cyan dye

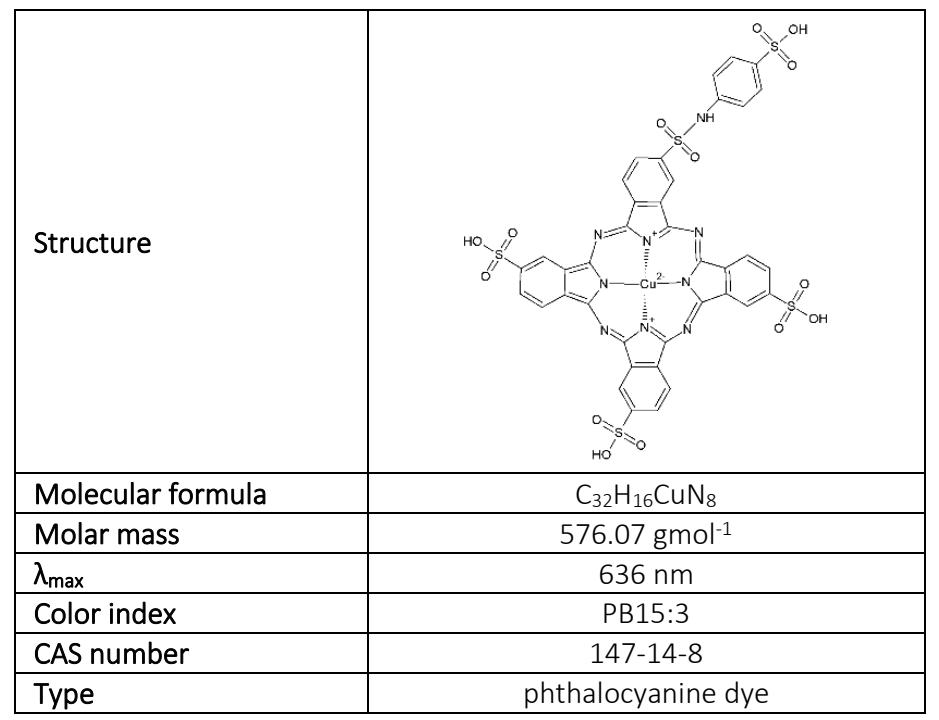

In this study, granulated polyethylene (PEg) microplastic particles were added to synthetic dye solution in order to investigate Fenton-like process efficiency for the removal of printing dye in the presence of MPs. MPs particles were purchased from Sigma Aldrich and basic physico-chemical properties of PEg are presented in Table 2.

Table 2: Physico-chemical properties of PEg (Lončarski, 2020; Tubić et al, 2019)

\begin{tabular}{|l|c|}
\hline PEg appearance & \\
& \\
\hline Particle size $(\mathrm{mm})$ & 3.0 \\
\hline Density $\left(\mathrm{gcm}^{-3}\right)$ & 0.918 \\
\hline Crystallinity $(\%)$ & 44.0 \\
\hline Melting Temperature $\left({ }^{\circ} \mathrm{C}\right)$ & 114 \\
\hline Glass Transition Temp. $\left({ }^{\circ} \mathrm{C}\right)$ & -120 \\
\hline
\end{tabular}




\subsection{Synthesis of Fenton catalyst}

"Green" synthesis method of nZVI particles was conducted by using green-tea leaves combined with iron chloride. Extraction procedure was carried out as described by Machado et al (2013). Extraction of $60 \mathrm{~g}$ green-tea leaves was performed with $1000 \mathrm{ml}$ of deionized water on a magnetic stirrer at temperature of $80^{\circ} \mathrm{C}$ for $60 \mathrm{~min}$. After extraction, the resulting mixture was filtered with Büchner Vacuum Filtration Funnel and mixed with $0.1 \mathrm{M} \mathrm{Fe}^{3+}$ solution in a volume ratio of 1:3. Mixture color turned from yellow to dark brown, indicating the formation of nanoparticles.

\subsection{Experimental procedure}

The lab scale of Fenton-like process was performed by a series of 15 experiments on a JAR test apparatus (FC6S Velp scientific, Italy) in a glass beaker containing $250 \mathrm{~mL}$ of Cyan dye solution at desired concentration (20-180 $\left.\mathrm{mgL}^{-1}\right)$. After the addition of $\mathrm{nZVI}$ in different concentrations $\left(0.75-60 \mathrm{mgL}^{-1}\right)$ and MPs particles (1$\left.10 \mathrm{gL}^{-1}\right)$, the $\mathrm{pH}$ adjustment (2-10) was conducted with $0.1 \mathrm{M} \mathrm{ccH}_{2} \mathrm{SO}_{4}$ and $0.1 \mathrm{M} \mathrm{NaOH}$ solution. The Fenton reaction was initiated by adding the hydrogen peroxide in various concentrations (1-11 $\mathrm{mM})$. The mixture was kept at a constant stirring of $120 \mathrm{rpm}$ at the temperature of $23^{\circ} \mathrm{C}$ for $60 \mathrm{~min}$ (Kecić et al, 2018a). The initial, as well as residual dye concentrations in the reaction mixture were determined by measuring the absorbance of the aqueous solutions at $636 \mathrm{~nm}$ by using UV/VIS spectrophotometer (UV 1800, Shimadzu, Japan). The decolorization efficiency was calculated according to equation (1):

$E(\%)=\frac{A_{0}-A_{t}}{A_{0}} * 100$

where: $A_{0}$ is the initial dye absorbance of Cyan dye aqueous solution; $A_{t}$ is absorbance of Cyan dye aqueous solution after Fenton-like process.

\subsection{Statistical analysis}

In this study, a novel three-level definitive screening design (DSD) approach was employed to investigate the printing dye removal in the presence of MPs particles by Fenton-like process. Five operating variables were included in one single experimental design: initial dye concentration, $\mathrm{nZVI}$ dosage, MPs concentration, $\mathrm{pH}$ and $\mathrm{H}_{2} \mathrm{O}_{2}$ concentration. Each factor had three levels representing the low (-), central (0), and high $(+)$, presented in Table 3. JMP 13 (SAS Institute, USA) software was used for the statistical analysis. What makes DSD a new class three-level screening design is a fact that it requires only one more experiment than twice the number of factors under analysis, which is of significant interest to practitioners. Still, it allows to estimate the main effects without any aliasing with each other or with two-factor interactions (Pereira et al, 2018).

Table 3: Process variables with experimental levels

\begin{tabular}{|l|c|c|c|c|}
\hline Variables & Unit & \multicolumn{3}{|c|}{ Levels } \\
\hline \multicolumn{2}{|c|}{} & -1 & 0 & +1 \\
\hline Dye concentration & $\left(\mathrm{mgL}^{-1}\right)$ & 20 & 100 & 180 \\
\hline nZVI dosage & $\left(\mathrm{mgL}^{-1}\right)$ & 0.75 & 30 & 60 \\
\hline $\mathrm{PEg}$ concentration & $\left(\mathrm{gL}^{-1}\right)$ & 1 & 5.5 & 10 \\
\hline $\mathrm{pH}$ & - & 2 & 6 & 10 \\
\hline $\mathrm{H}_{2} \mathrm{O}_{2}$ concentration & $(\mathrm{mM})$ & 1 & 6 & 11 \\
\hline
\end{tabular}

\section{RESULTS AND DISCUSSIONS}

Table 4 shows the 5 -variable DSD matrix designed with JMP 13 program and obtained Fenton process efficiencies (\%) for 15 experimental runs. It is observed that the maximum and minimum decolorization efficiencies during Fenton-like process are achieved under different sets of process conditions, which confirms the assumption that dye removal process mostly depends on the applied experimental conditions. When compared with classical fractional factorial designs, DSD's have the advantage of estimating independently the main and the quadratic effect, as well as of being unaliased with two-factors interactions (Pereira et al, 2018). 
Table 4: Experimental design layout and observed response

\begin{tabular}{|l|c|c|c|c|c|c|}
\hline No. & $\begin{array}{c}\text { Dye } \\
\text { concentration } \\
\left(\mathrm{mgL}^{-1}\right)\end{array}$ & $\begin{array}{c}\mathrm{nZVI} \text { dosage } \\
\left(\mathrm{mgL}^{-1}\right)\end{array}$ & $\begin{array}{c}\mathrm{PEg} \\
\text { concentration } \\
\left(\mathrm{gL}^{-1}\right)\end{array}$ & $\mathbf{p H}$ & $\begin{array}{c}\mathrm{H}_{2} \mathrm{O}_{2} \\
\text { concentration } \\
(\mathrm{mM})\end{array}$ & $\begin{array}{c}\text { Fenton process } \\
\text { efficiency (\%) }\end{array}$ \\
\hline 1 & 100 & 60 & 10 & 10 & 11 & 1.41 \\
\hline 2 & 100 & 0.75 & 1 & 2 & 1 & 81.54 \\
\hline 3 & 180 & 30 & 1 & 10 & 11 & 0.74 \\
\hline 4 & 20 & 30 & 10 & 2 & 1 & 18.99 \\
\hline 5 & 180 & 0.75 & 5.5 & 2 & 11 & 69.41 \\
\hline 6 & 20 & 60 & 5.5 & 10 & 1 & 1.73 \\
\hline 7 & 180 & 60 & 1 & 5,5 & 1 & 84.76 \\
\hline 8 & 20 & 0.75 & 10 & 5,5 & 11 & 0.68 \\
\hline 9 & 180 & 60 & 10 & 2 & 6 & 91.67 \\
\hline 10 & 20 & 0.75 & 1 & 10 & 6 & 1.58 \\
\hline 11 & 180 & 0.75 & 10 & 10 & 1 & 1.70 \\
\hline 12 & 20 & 60 & 1 & 2 & 11 & 0.15 \\
\hline 13 & 100 & 30 & 5.5 & 5,5 & 6 & 30.54 \\
\hline 14 & 100 & 30 & 5.5 & 5,5 & 6 & 33.43 \\
\hline 15 & 100 & 30 & 5.5 & 5,5 & 6 & 29.94 \\
\hline
\end{tabular}

The adopted regression model contained eleven terms. As shown in Table 5, the adopted regression model explains approximately $99.9 \%$ of variance in the observed Fenton efficiency values. The value of adjusted $\mathrm{R}^{2}$ is $99.8 \%$, which reveals good relationship between the expected values and the actual values. Compared to mean of response, root mean square error is small, indicating good fit and accuracy of model prediction. Results of ANOVA test shown in Table 6 confirmed the significance of the adopted regression model (the value of the parameter $F<0.0001)$.

Table 5: Summary of fit

\begin{tabular}{|l|c|}
\hline Source & Value \\
\hline$R^{2}$ & 0.999 \\
\hline$R^{2}$ Adj & 0.998 \\
\hline Root Mean Square Error & 1.361 \\
\hline Mean of Response & 29.885 \\
\hline
\end{tabular}

Table 6: ANOVA

\begin{tabular}{|l|c|c|c|c|}
\hline Source & Degrees of freedom & Sum of Squares & Mean Square & F parameter \\
\hline Model & 10 & 16969.039 & 1696.900 & 916.245 \\
\hline Error & 4 & 7.408 & 1.850 & Prob $>\mathrm{F}$ \\
\hline C. Total & 14 & 16976.447 & - & $<0.0001$ \\
\hline
\end{tabular}

Based on the estimated parameter and standard error values, the statistically significant factors that contribute the most to the efficiency of Cyan dye removal in Fenton-like process were determined (Table 7 - bolded values). Statistical analysis revealed that all main process parameters are statistically significant and contribute to the decolorization efficiency. The results demonstrated that dye concentration, nZVI dosage and interaction effect between PEg concentration and $\mathrm{H}_{2} \mathrm{O}_{2}$ concentration, dye concentration and $n Z \mathrm{VI}$ dosage as well as $\mathrm{pH}$ and $\mathrm{H}_{2} \mathrm{O}_{2}$ concentration have a positive influence on the Fenton process efficiency, while other variables have a negative effect. Furthermore, all single terms are a part of four significant two-way interactions, whereby dye concentration, $\mathrm{pH}$ and $\mathrm{H}_{2} \mathrm{O}_{2}$ concentrations are involved in two significant interactions.

Based on Table 7, a surface response plots of significant two-way interactions in the model are shown in Figure 1. From the surface plot diagram (Figure 1a) it follows that maximal Fenton process efficiency is reached when $\mathrm{nZVI}$ dosage is kept at its high level $\left(60 \mathrm{mgL}^{-1}\right)$, while dye concentration increases from 20 to $180 \mathrm{mgL}^{-1}$. However, maintained at low level $(1 \mathrm{mM}), \mathrm{H}_{2} \mathrm{O}_{2}$ concentration exhibits the most pronounced influence on the impact of PEg concentration on dye removal (Figure 1c). The phenomenon can be ascribed to the fact that dye removal can be achieved with both advanced oxidation process and adsorption process of dye on MPs surface. 
Table 7: Parameter estimates sorted by statistical significance

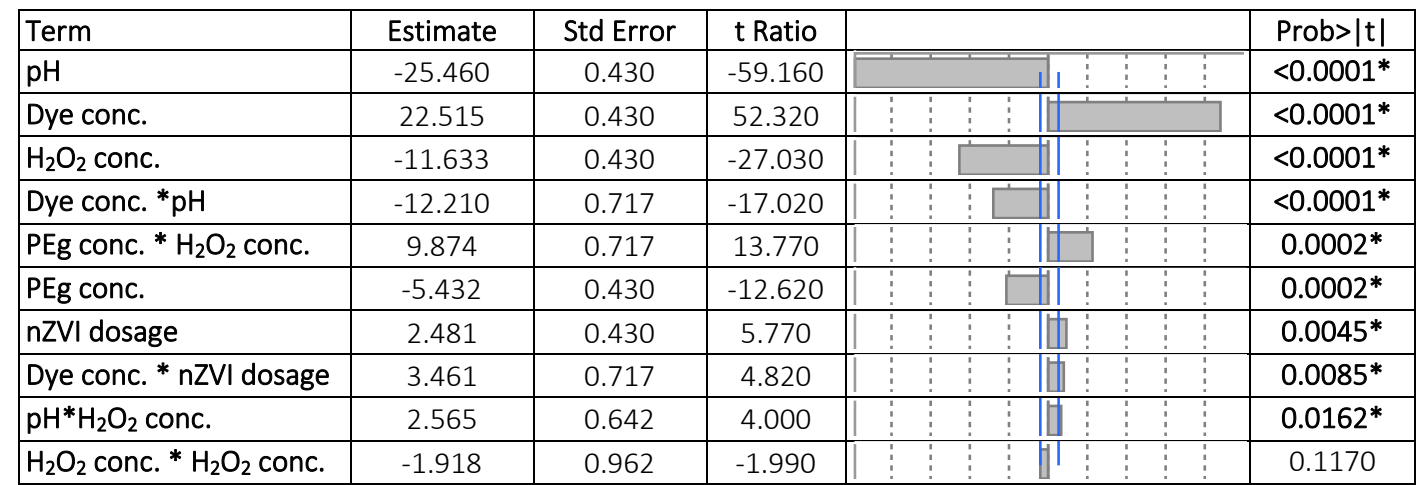

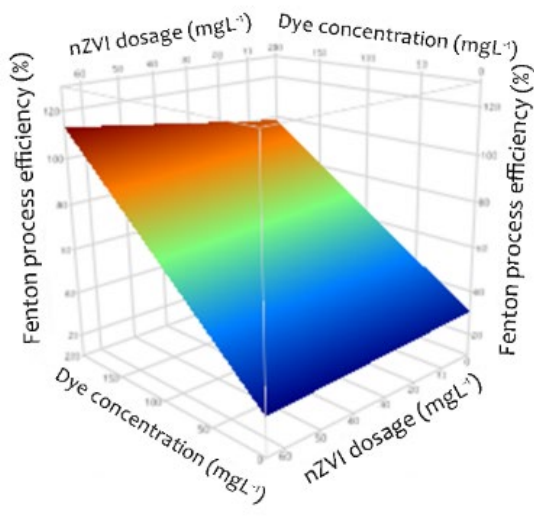

a)

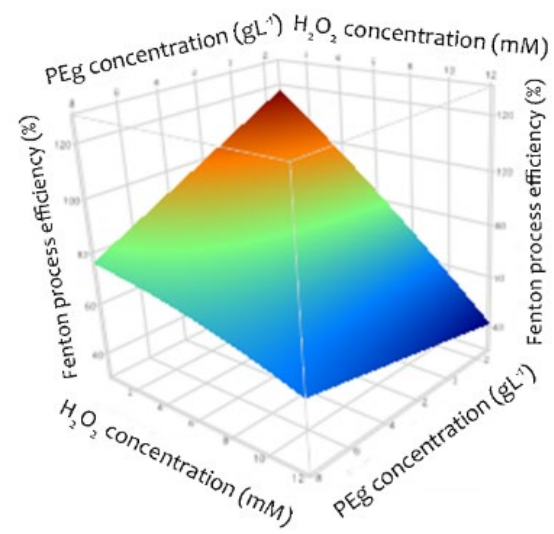

c)

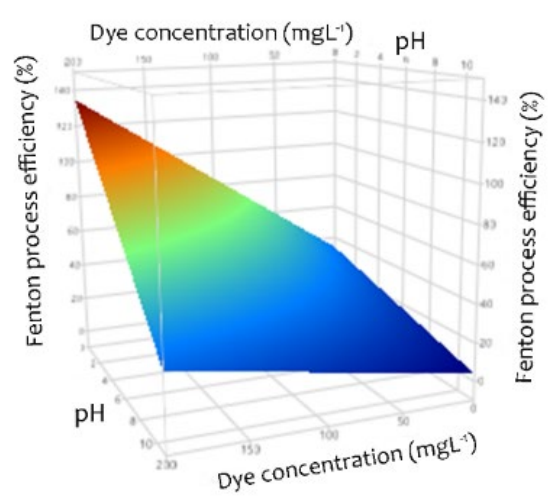

b)

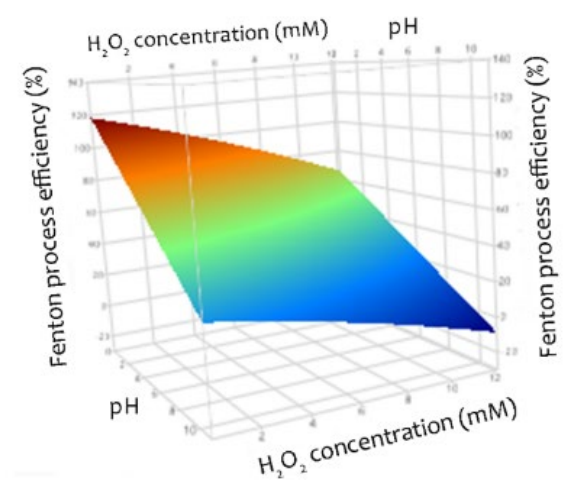

d)

Figure 1: Surface response plots illustrating two significant interactions between: a) dye concentration and nZVI dosage; b) dye concentration and $\mathrm{pH}$; c) PEg concentration and $\mathrm{H}_{2} \mathrm{O}_{2}$ concentration; d) $\mathrm{pH}$ and $\mathrm{H}_{2} \mathrm{O}_{2}$ concentration

Prediction profiler with optimal settings is shown in Figure 2. The optimization plot graphically illustrates how the Fenton process efficiency changes as a function of one of the variables, while all other variables remain constant. According to optimization results, maximum Fenton process efficiency of $92 \%$ is obtained for the following settings: $155 \mathrm{mgL}^{-1}$ of Cyan dye concentration, $55 \mathrm{mgL}^{-1}$ of nZVI dosage, $2.35 \mathrm{gL}^{-1} \mathrm{of} \mathrm{PEg}$ concentration, $2 \mathrm{mM}$ of $\mathrm{H}_{2} \mathrm{O}_{2}$ concentration and $\mathrm{pH}$ 2.5. This confirms that the process efficiency increases with $\mathrm{H}_{2} \mathrm{O}_{2}$ and $\mathrm{pH}$ decreasing. 


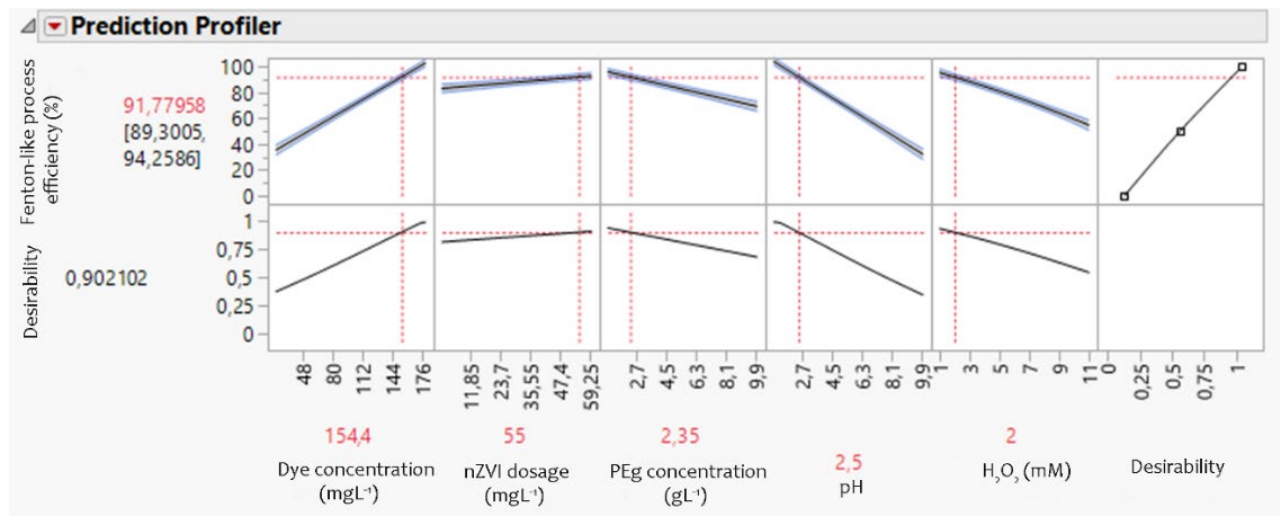

Figure 2: Optimization diagram for Fenton-like process

In the study conducted by Kecić et al (2018b), Cyan dye removal with nZVI-induced Fenton process without MPs particles resulted with $87 \%$. The obtained higher Fenton process efficiency in this experiment is probably due to the partial dye adsorption on MPs surface, indicating that the presence of MPs particles in wastewater may contribute to higher Fenton process efficiency than actually obtained. Certainly, future studies must include printing wastewater treatments containing dyes and MPs of various types and concentrations.

\section{CONCLUSIONS}

In this study, Fenton-like treatment of Cyan water-based printing dye with the addition of microplastic in a form of granulated polyethylene was investigated. A novel statistical method, definitive screening design, was used in order to allow screening and preliminary optimization in a single experiment. The method proposed enables efficient treatment of synthetic aqueous solutions in the presence of microplastics, optimized for maximum decolorization efficiency of $92 \%$ by the adopted statistical model. The results confirmed the significant influence of all main process parameters on decolorization efficiency, as well as four significant two-way interaction. Furthermore, higher decolorization efficiency was obtained in comparison to Fenton-like process without the addition of microplastic, indicating a possible adsorption dye mechanism with the simultaneous Fenton process conduction. Nevertheless, further investigation should be directed towards the evaluation efficiency of various treatments for the synthetic dye removal in the presence of microplastic in wastewater treatments, while focusing on possible influence of microplastic on desorption of synthetic dyes into the aquatic environment and assessment of effluent toxicity before and after treatment.

\section{ACKNOWLEDGMENTS}

This research has been supported by the Provincial Secretariat for Science and Technological Development, Autonomous Province of Vojvodina through the project: "Synthetic dye removal in the presence of microplastics in advanced water treatment" (Grant No. 142-451-3186/2020-03).

\section{REFERENCES}

[1] Atrous, M., Sellaoui, L., Bouzid, M., Lima, E., Thue P., Bonilla-Petriciolet, A., Lamine, A.: "Adsorption of dyes acid red 1 and acid green 25 on grafted clay: Modeling and statistical physics interpretation", Journal of Molecular Liquids 294, 111610, 2019. doi: 10.1016/j.molliq.2019.111610.

[2] Collivignarelli, M., Abba, A., Miino, M., Damiani, S.: "Treatments for color removal from wastewater: State of the art", Journal of Environmental Management 236, 727-745, 2019. doi: 10.1016/j.jenvman.2018.11.094.

[3] Feng, Q., Gao, B., Yue, Q., Guo, K.: “Flocculation performance of papermaking sludge-based flocculants in different dye wastewater treatment: Comparison with commercial lignin and coagulants", Chemosphere 262, 128416, 2021. doi: 10.1016/j.chemosphere.2020.128416.

[4] Gulliver, T.: "Degradation of PHB and PE microbeads in aerobic and anaerobic biological wastewater treatment microcosms", PhD thesis, Colorado School of Mines, Arthur Lakes Library, 2017. 
[5] Hendaoui, K., Trabelsi-Ayadi, M., Ayari, F.: "Optimization and mechanisms analysis of Indigo dye removal using continuous electrocoagulation", Chinese Journal of Chemical Engineering, 2020. doi: 10.1016/j.cjche.2020.07.065, 2020.

[6] Kecić, V., Kerkez, Đ., Prica, M., Lužanin, O., Bečelić-Tomin, M., Tomašević Pilipović, D., Dalamcija, B.: "Optimization of azo printing dye removal with oak leaves-nZVI/ $\mathrm{H}_{2} \mathrm{O}_{2}$ system using statistically designed experiment", Journal of Cleaner Production 202, 65-80, 2018a. doi: 10.1016/j.jclepro.2018.08.117.

[7] Kecić, V., Prica, M., Kerkez, Đ., Lužanin, O., Bečelić-Tomin, M., Tomašević Pilipović D., Leovac Maćerak, A.: Definitive screening design for the optimization of flexographic water-based Cyan dye removal from aqueous solution by $\mathrm{nZVI-induced} \mathrm{Fenton} \mathrm{process.} \mathrm{Proceedings} \mathrm{of} 9^{\text {th }}$ International Symposium on Graphic Engineering and Design 2018b, (GRID: Novi Sad, Serbia, 2018), pages 161-167.

[8] Lončarski, M.: "Impact of physicochemical properties of microplastics and selected persistent organic pollutants on interactions in the aqueous matrix", PhD thessis, University of Novi Sad, Faculty of Sciences, 2020.

[9] Machado, S., Pinto, S., Grosso, J., Nouws, H., Albergaria, J., Delerue-Matos, C.: "Green production of zero-valent iron nanoparticles using tree leaf extracts", Science of the Total Environment 445-446, 1-8, 2013. doi: 10.1016/j.scitotenv.2012.12.033.

[10] Mojtabavi, S., Khoshayand, M., Fazeli, M., Samadi, N., Faramarzi, M.: "Combination of thermal and biological treatments for bio-removal and detoxification of some recalcitrant synthetic dyes by betaine-induced thermostabilized laccase", Environmental Technology \& Innovation 20, 101046, 2020. doi: 10.1016/j.eti.2020.101046.

[11] Papadopoulos, K., Argyriou, R., Economou, C., Charalampous, N., Dailianis, S., Tatoulis, T., Tekerlekopoulou, A., Vayenas D.: "Treatment of printing ink wastewater using electrocoagulation", 2019. Journal of Enviornmental Management 237, 442-448, 2019. doi: 10.1016/j.jenvman.2019.02.080.

[12] Pekarovicova, A., Husovska, V.: "Printing ink formulations", Printing on Polymers 41-52, 2016. doi: 10.1016/B978-0-323-37468-2.00015-4.

[13] Pereira, A., Reis, M., Leca, J., Rodrigues, P., Marques, J.: “Definitive Screening Designs and latent variable modelling for the optimization of solid phase microextraction (SPME): Case study Quantification of volatile fatty acids in wines", Chemometrics and Intelligent Laboratory Systems 179, 73-81, 2018. doi: 10.1016/j.chemolab.2018.06.010.

[14] Somalu, M., Muchtar, A., Daud, W., Brandon, N.: "Screen-printing inks for the fabrication of solid oxide fuel cell films: a review", Renewable and Sustainable Energy Reviews 75, 426-439, 2017. doi: 10.1016/j.rser.2016.11.008.

[15] Tubić, A., Lončarski, M., Maletić, S., Molnar Jazić, J., Watson, M., Tričković, J., Agbaba, J.: "Significance of Chlorinated Phenols Adsorption on Plastics and Bioplastics during Water Treatment", Water 11, 2358, 2019. doi: 10.3390/w11112358.

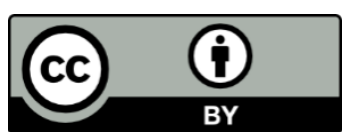

(C) 2020 Authors. Published by the University of Novi Sad, Faculty of Technical Sciences, Department of Graphic Engineering and Design. This article is an open access article distributed under the terms and conditions of the Creative Commons Attribution license 3.0 Serbia (http://creativecommons.org/licenses/by/3.0/rs/). 